\title{
Impact of frailty on periprocedural health care utilization in patients undergoing transcatheter edge-to-edge mitral valve repair
}

\author{
Christos Iliadis $^{1}$ ([) $\cdot$ Leandra Schwabe $^{2} \cdot$ Dirk Müller $^{3} \cdot$ Stephanie Stock $^{3} \cdot$ Stephan Baldus $^{1} \cdot$ Roman Pfister $^{1}$
}

Received: 10 August 2020 / Accepted: 2 December 2020 / Published online: 17 December 2020

(c) The Author(s) 2020

\begin{abstract}
Background Frailty is a common characteristic of patients undergoing transcatheter mitral valve repair (TMVR). It is unclear whether the physical vulnerability of frail patients translates into increased procedural health care utilization.

Methods and results Frailty was assessed using the Fried criteria in 229 patients undergoing TMVR using the MitraClip system at our institution and associations with total costs and costs by cost centers within the hospital incurred during periprocedural hospitalization were examined. Frail patients $(n=107,47 \%)$ compared to non-frail patients showed significantly higher total costs [median/interquartile range, excluding implant costs: 7,337 €(5,911-9,814) vs 6,238 € (5,584-7,499), $p=0.001]$, with a difference in means of $2,317 €$. Frailty was the only clinical baseline characteristic with significant association with total costs. Higher total costs in frail patients were attributable primarily to longer stay on intermediate/intensive care unit (3.8 \pm 5.7 days in frail vs $2.1 \pm 1.7$ days in non-frail, $p=0.003)$, but also to costs of clinical chemistry and physiotherapy. The prolonged stay on intermediate/intensive care unit in frail patients was attributable to postprocedural complications such as bleeding, kidney injury, infections and cardiovascular instability.

Conclusion Frailty is associated with a mean $32 \%$ increase of hospital costs in patients undergoing TMVR, which is primarily the result of a prolonged recovery and increased vulnerability to complications. These findings are valuable for a hospital's
\end{abstract}

Christos Iliadis and Leandra Schwabe contributed equally to this study.

All authors take responsibility for all aspects of the reliability and freedom from bias of the data presented and their discussed interpretation.

Relationship with industry and other entities: S.B. has received lecture honoraria from Edwards Lifesciences, Bayer Vital, CVRx, MSD Sharp\&Dome GmbH, JenaValve Technology, Abbott and research grant from IcoVifor, Symetis SA, Pfizer, JenaValve Technology, Valtech, OptumInsight, Biotronik and Abbott, "modest", outside the submitted work. R.P. has received speaker and consultant honoraria by Abbott and Edwards Lifesciences, "modest", outside the submitted work. C.I. has received travel support by Abbott and consultant honoraria by Abbott and Edwards Lifesciences, "modest", outside the submitted work. L.S., D.M. and S.S. have no relationship with industry and other entities.

Supplementary Information The online version contains supplementary material available at https://doi.org/10.1007/s0039 2-020-01789-5.

Christos Iliadis christos.iliadis@uk-koeln.de

1 Department III of Internal Medicine, Faculty of Medicine and University Hospital Cologne, Heart Center, University of Cologne, Kerpener Strasse 62, 50937 Cologne, Germany

2 Department of Diagnostic and Interventional Radiology, Faculty of Medicine and University Hospital Cologne, University of Cologne, Cologne, Germany

3 Institute for Health Economics and Clinical Epidemiology, University of Cologne, Cologne, Germany 
total cost calculation and resource allocation planning. Since frailty is regarded a potentially reversible health state, preventive interventions may help reduce costs in frail patients.

\section{Graphic abstract}

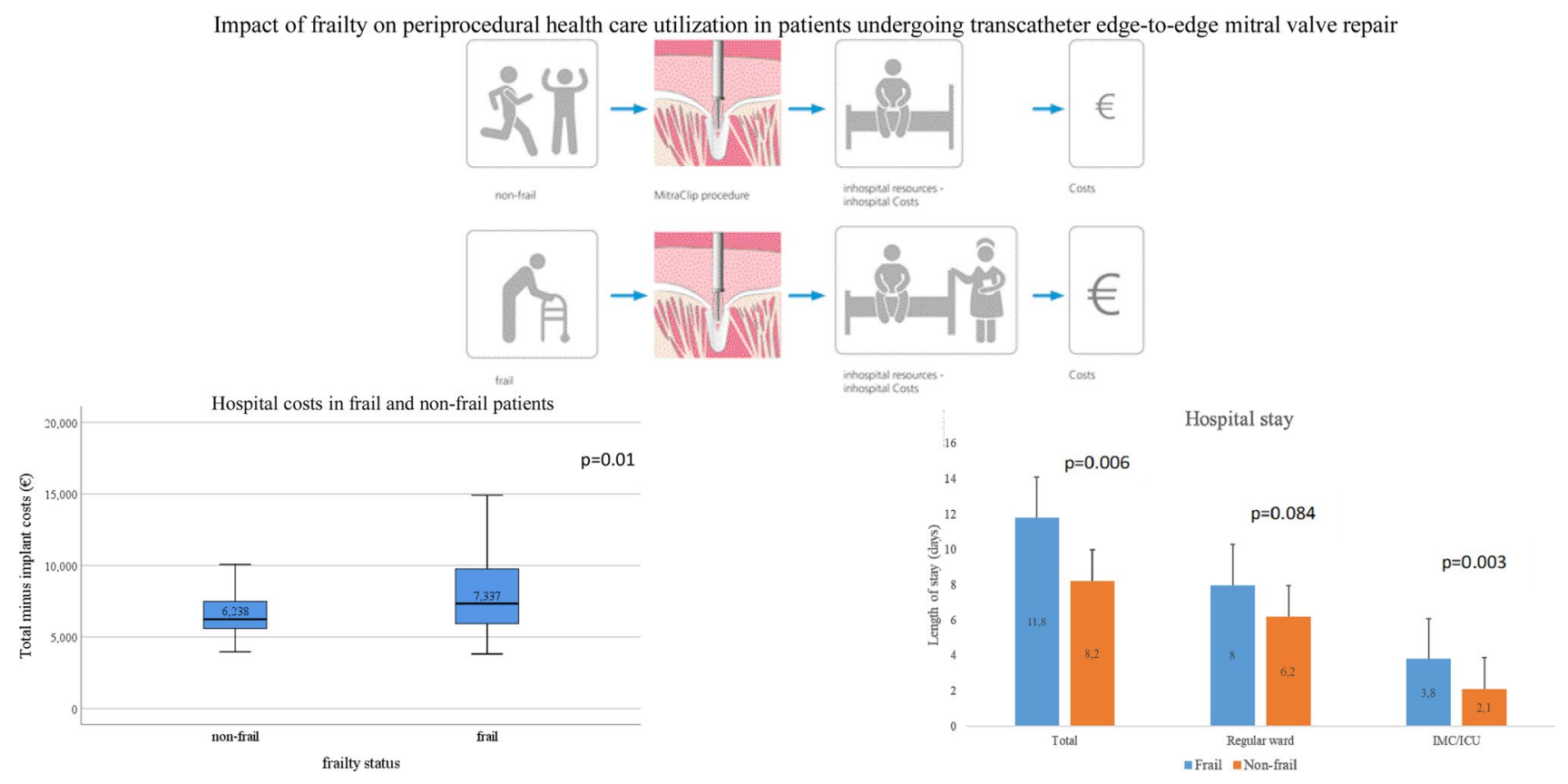

Keywords MitraClip · Frailty $\cdot$ Hospital costs

\section{Introduction}

The implications of frailty for the health care sector gain increasing attention in the context of ageing populations. Frailty is a complex clinical syndrome, which describes a decrease of physiological reserves that come along with an increased vulnerability to stressors [1]. Although frailty increases with aging, and is usually regarded as geriatric syndrome, it reflects a functional impairment beyond the chronological age [2]. For example, single severe organic disease or high cumulative comorbidity also contribute to the development of frailty [3].

Potential medical stressors where an increased vulnerability of frail people might become particularly relevant are surgery or interventional procedures. In patients undergoing percutaneous coronary intervention or cardiac surgery, frailty was associated with higher mortality, vascular and bleeding complications and renal failure [4-7]. These procedural complications translated into increased hospitalization costs in frail patients $[8,9]$. Transcatheter valve interventions such as transcatheter aortic valve implantation [10] or transcatheter mitral valve repair (TMVR) were developed to decrease medical stress for patients $[11,12]$. As consequence, this means that frailty is a frequent clinical reason to decide for a transcatheter approach and against surgical valve therapy and almost every second patient undergoing TAVI or TMVR is frail $[13,14]$.

So far it is unclear whether "low stress" procedures like TMVR have an impact on the complication rate, recovery from complications and resulting treatment costs in highly vulnerable patients. We have recently demonstrated that the risk of major cardiac or vascular complications was not increased in frail compared to non-frail patients undergoing TMVR [15]. However, major complications are overall very rare after TMVR and frailty might affect health care utilization through minor procedural or procedure independent complications following TMVR. The knowledge of determinants of treatment costs and underlying causes is of major relevance for all health care stakeholders. The aim of this study was to examine the association of frailty status with hospital related costs in consecutive patients undergoing TMVR with MitraClip at our institution.

\section{Methods}

Consecutive adult patients undergoing TMVR using the MitraClip system (Abbott Vascular, Santa Clara, California, USA) at our institution between May 2014 and October 
2016 were eligible for this retrospective analysis of prospectively assessed data on frailty in patients undergoing TMVR. Treatment decision for TMVR with MitraClip was taken by a multidisciplinary heart team after preoperative risk assessment based on objective risk scores, clinical parameters and morphological suitability for MitraClip according to current guidelines [16]. All patients underwent TMVR in general anesthesia. Extubation in the cath lab is pursued in every patient. By default, all patients are transferred to the cardiology intermediate care unit (IMC) for at least $24 \mathrm{~h}$ after the procedure. If medically indicated, monitoring on the IMC can be extended to more than $24 \mathrm{~h}$, and patients could be transferred to the intensive care unit (ICU) post-procedurally if extubation was unsuccessful or in the case of severe haemodynamic compromise. Written informed consent for participation was obtained from all patients included in this study. The study was approved by the local ethics committee of the University of Cologne (reference 14-116, German Registry of Clinical Trials registration DRKS00006194).

Frailty status using the Fried criteria was prospectively assessed before the MitraClip procedure as reported earlier [15]. Briefly, the five components of the frailty syndrome (unintentional weight loss, weakness, exhaustion, slowness and low physical activity) were assessed, and 1 point was scored for each criterion met to specification. Patients meeting at least 3 of the 5 criteria were classified as frail. All treating physicians were blinded to the frailty status. For confirmatory analysis we used a second definition of frailty based on disability in Instrumental Activities of Daily Life (IADL) as recommended by the Mitral Valve Academic Research Consortium [17]. Disabilities in IADL have been shown to correlate with physical frailty in elderly people [18, 19]. Since a validated threshold of IADL for frailty definition is lacking, we pragmatically defined a frail status by the group median of the IADL score which corresponds to a disability in more than two IADL domains. Prespecified baseline clinical characteristics were extracted from the patient record. The reason for a prolonged IMC/ICU stay which we defined as more than two days was assessed retrospectively from records using predefined categories: (a) postprocedural minor or major bleeding according to MVARC (Mitral Valve Academic Research Consortium); (b) an acute kidney injury requiring haemodialysis; (c) an acute infection with antibiotic treatment; (d) haemodynamic instability which required inotropes or vasopressors, or arrhythmias leading to haemodynamic compromise; (e) respiratory failure with need of mechanical or non-invasive ventilation and (f) in absence of medical reasons logistic causes, meaning no vacancy to transfer the patient to the normal ward. All cost and reimbursement data were provided by the department of controlling of the University Hospital of Cologne. Total hospital costs were calculated as the sum of all incurred costs during hospital stay for elective TMVR from the day of hospital admission to discharge, including personnel expenses, material costs and costs for infrastructure. Personnel expenses for physician and nursing services, overhead costs for medication, other medical supply and medical and not-medical infrastructure were time based allocated to a patient. Revenues were calculated according to the German Diagnosis Related Groups (G-DRG) system on a case-based lump sum.

Mean and standard deviation or median and interquartile range (where data were not normally distributed) was used for continuous variables and frequency with percentage for categorical variables. $t$ test (and Welch's $t$ test in case of unequal variances) or Mann-Whitney $U$ test or $\mathrm{Chi}^{2}$-test was used for comparison between groups. All cost variables showed a highly skewed distribution and were described as median and interquartile range. However, we also present the difference in mean costs of the two groups which is interesting from the economic point of view. Since cost distribution was skewed, reciprocal transformation was used to achieve normal distribution. Univariable and multivariable linear regression analyses were applied to identify significant preoperative predictors of total costs minus implant costs. The statistical analyses were performed using IBM ${ }^{\circledR}$ SPSS $®$ Statistics 25 (SPSS Inc., Chicago, Illinois, USA).

\section{Results}

\section{Baseline characteristics}

229 patients (126 male and 103 female) with a mean age of $78 \pm 8$ years were included in the analysis and $46.7 \%$ were classified as frail according to Fried criteria. Table 1 shows the patients' baseline characteristics. Frail patients were found to be of significantly higher age and had a worse functional status regarding NYHA functional class (NYHA class III or IV in $95 \%$ vs. $80 \%$ of patients) compared to non-frail patients. Frail patients had significantly higher EuroScore II and less previous cardiac surgery compared to non-frail patients ( $28 \%$ vs. $44 \%$ ). Regarding sex and selected comorbidities-as reduced ejection fraction, diabetes mellitus or chronic obstructive pulmonary disease- there was no significant difference between the two groups. In contrary, frail patients had more severe renal impairment. Frailty according to Fried showed a significant association with frailty defined by disability in IADL. The difference in rate of urgent referrals was higher in frail patients which was of borderline significance. The total length of hospital stay and IMC/ICU stay were significantly increased in frail patients (Fig. 1).

\section{Costs and revenues}

Frail patients showed significantly higher total costs $[28,225 €(26,832-31,756)]$ compared to non-frail patients 
Table 1 Comparison of clinical characteristics between frail and non-frail patients

\begin{tabular}{|c|c|c|c|}
\hline & Frail $(n=107)$ & Non-frail $(n=122)$ & $p$ value \\
\hline \multicolumn{4}{|l|}{ Baseline } \\
\hline Age, years & $79 \pm 7$ & $77 \pm 9$ & 0.02 \\
\hline Male, $n(\%)$ & $52(49)$ & $74(61)$ & 0.07 \\
\hline $\mathrm{BMI}\left(\mathrm{kg} / \mathrm{m}^{2}\right)$ & $25.6 \pm 5.7$ & $25.2 \pm 5.6$ & 0.45 \\
\hline Logistic Euroscore & $22.1 \pm 15.3$ & $19.2 \pm 15.2$ & 0.09 \\
\hline Euroscore II & $9.2 \pm 7$ & $7.4 \pm 6.6$ & 0.008 \\
\hline Secondary MR aetiology, $n(\%)$ & $59(55)$ & $72(59)$ & 0.83 \\
\hline Hypertension, $n(\%)$ & $80(75)$ & $89(73)$ & 0.76 \\
\hline Diabetes mellitus, $n(\%)$ & $35(33)$ & $27(22)$ & 0.07 \\
\hline Previous stroke/TIA, $n(\%)$ & $13(12)$ & $17(14)$ & 0.69 \\
\hline Previous myocardial infarction, $n(\%)$ & $33(31)$ & $35(29)$ & 0.72 \\
\hline Coronary artery disease, $n(\%)$ & $65(61)$ & $73(60)$ & 0.89 \\
\hline Previous cardiac surgery, $n(\%)$ & $30(28)$ & $54(44)$ & 0.01 \\
\hline Previous ICD, $n(\%)$ & $16(15)$ & $27(22)$ & 0.17 \\
\hline Previous CRT, $n(\%)$ & $24(22)$ & $21(17)$ & 0.32 \\
\hline PAOD, $n(\%)$ & $13(12)$ & $13(11)$ & 0.72 \\
\hline COPD, $n(\%)$ & $19(18)$ & $18(15)$ & 0.52 \\
\hline Atrial fibrillation, $n(\%)$ & $70(65)$ & $68(56)$ & 0.14 \\
\hline Malignancy, $n(\%)$ & $16(15)$ & $21(17)$ & 0.64 \\
\hline $\operatorname{GFR}\left(\mathrm{ml} / \mathrm{min} / 1.73 \mathrm{~m}^{2}\right)$ & $41.6 \pm 20$ & $51.2 \pm 20$ & 0.001 \\
\hline $\mathrm{EF}>50 \%, n(\%)$ & $56(52)$ & $54(44)$ & 0.4 \\
\hline NYHA, $n(\%)$ & & & $<0.001$ \\
\hline $\mathrm{I} / \mathrm{II}$ & $5(5)$ & $24(20)$ & \\
\hline III/IV & $102(95)$ & $98(80)$ & \\
\hline Frailty by IADL disability & $71(66.4 \%)$ & $40(32.8 \%)$ & $<0.001$ \\
\hline Urgent referral status, $n(\%)$ & $18(17)$ & $10(8)$ & 0.047 \\
\hline Total length of stay (days) & $11.8 \pm 9.7$ & $8.2 \pm 9.9$ & $<0.001$ \\
\hline Stay on regular ward & $8.0 \pm 7.3$ & $6.2 \pm 8.7$ & 0.03 \\
\hline Stay on intensive/intermediate care unit & $3.8 \pm 5.7$ & $2.1 \pm 1.7$ & $<0.001$ \\
\hline
\end{tabular}

Data are presented as arithmetic mean and standard deviation or frequency and percentage. Comparison between groups by $t$ test or $\mathrm{Chi}^{2}$-test

$B M I$ body-mass index, $C O P D$ chronic obstructive pulmonary disease, $E F$ ejection fraction, $G F R$ glomerular filtration rate, $I A D L$ instrumental activities of daily life, $M R$ mitral regurgitation, MVARC mitral valve academic research consortium, NYHA New York heart association, PAOD peripheral artery occlusive disease, TIA transient ischemic attack
$[27,459 €(26,457-28,377), p=0.002$, Table 2]. Since the implant (MitraClip device) was by far the largest cost item $(21,000 €, 72 \%$ of all costs) an additional analysis was performed, focusing on total costs excluding implant costs. Still, costs were significantly increased in frail patients $[7,337 €(5,911-9,814)]$ compared to non-frail patients $[6,238 €(5,584-7,499)](p=0.001)$, with a difference of means of $2,317 €$ (Fig. 2). The revenues were significantly different between frail and non-frail patients $[31,959 €$ $(31,825-32,954)]$ vs. [31,825 $€(31,638-32,834), p=0.034]$, with a difference of means of $99 €$. In $22.4 \%$ of cases, the revenue was not cost-covering in frail patients compared to $6.6 \%$ in non-frail patients $(p=0.001)$.

All baseline characteristics of Table 1 were examined in univariate linear regression with total minus implant costs as dependent variable. All significant variables of univariate analysis (Euroscore II, frailty, glomerular filtration rate and urgent referral status) were examined in a multivariate model. Frailty remained a significant factor in predicting total costs minus implant costs $(p=0.04$ for frailty in linear regression analysis).

When defining frailty by disability in IADL, results were virtually the same. Patients with disability had significantly higher total costs $[27,937 €(26,832-30,505)$ vs. $27,401 €$ $(26,428-29,097), p=0.03]$ and significantly higher total costs excluding implant costs $[7,080 €(5,879-9,105)$ vs. $6,351 €(5,611-7,812), p=0.02]$.

To evaluate the impact of cost outliers, the total cost analysis was repeated after excluding high cost cases (total costs $>40,000 €)$. Cost outliers accounted for $4 \%$ of the 
Fig. 1 Days spent in the hospital: total, regular ward and intermediate/intensive care unit

\section{Hospital stay}

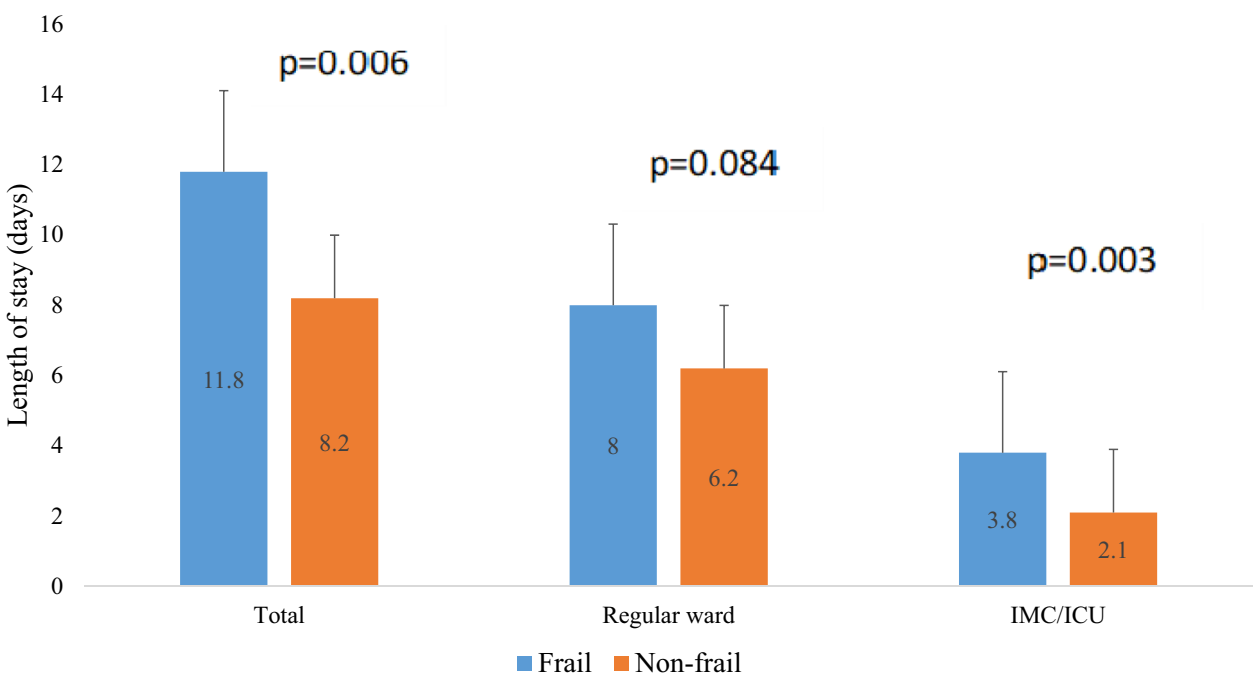

Table 2 Comparison of hospital costs by operated units and revenue between frail and nonfrail patients

\begin{tabular}{lccc}
\hline Hospital costs $(€)$ & Frail $(n=107)$ & Non-frail $(n=122)$ & $p$ value \\
\hline Total costs & $28,225(26,832-31,756)$ & $27,459(26,457-28,377)$ & 0.002 \\
& {$[30,712 \pm 7,754]$} & {$[28,240 \pm 4,467]$} & \\
Total costs minus implant costs & $7,337(5,911-9,814)$ & $6,238(5,584-7,499)$ & 0.001 \\
& {$[9,449 \pm 7,188]$} & {$[7,132 \pm 4,344]$} & \\
Regular ward & $1,670(1,135-2,543)$ & $1,404(980-1,843)$ & 0.011 \\
& {$[2,258 \pm 1,902]$} & {$[1,746 \pm 2,274]$} & \\
Intermediate/intensive care unit & $1,401(863-2,468)$ & $1,294(746-1,459)$ & 0.001 \\
& {$[2,973 \pm 5,057]$} & {$[1,438 \pm 1,269]$} & \\
Anaesthesia & $570(457-706)[605 \pm 368]$ & $568(463-727)[600 \pm 192]$ & 0.671 \\
Cardiac catheter laboratory & $23,931(22,935-24,403)$ & $23,821(23,185-24,450)$ & 0.931 \\
& {$[23,867 \pm 1,700]$} & {$[23,867 \pm 1,222]$} & \\
Radiology & $28(13-75)[90 \pm 154]$ & $26(0-50)[97 \pm 230]$ & 0.049 \\
Clinical chemistry & $223(161-422)[385 \pm 451]$ & $173(140-239)[263 \pm 302]$ & 0.002 \\
Other diagnostics & $141(93-288)[188 \pm 134]$ & $108(93-242)[160 \pm 125]$ & 0.092 \\
Physiotherapy & $31(6-77)[101 \pm 229]$ & $9(0-35)[31 \pm 58]$ & 0.034 \\
Revenues & $31,959(31,825-32,954)$ & $31,825(31,638-32,834)$ & 0.034 \\
& {$[32,964 \pm 8,208]$} & {$[32,865 \pm 10,185]$} & \\
\hline
\end{tabular}

Data are presented as median and interquartile range [mean \pm standard deviation] Comparison between groups by Mann-Whitney- $U$ test

$B M I$ body-mass index, $C O P D$ chronic obstructive pulmonary disease, $E F$ ejection fraction, $G F R$ glomerular filtration rate, $I A D L$ instrumental activities of daily life, $M R$ mitral regurgitation, $M V A R C$ mitral valve academic research consortium, NYHA New York heart association, PAOD peripheral artery occlusive disease, TIA transient ischemic attack

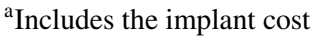

total study population. Considerably high costs occurred in patients with urgent MitraClip with cardiac decompensation and prolonged hospital stay due to the need for recompensation; prolonged respiratory failure with need for respiratory support; infection leading to severe sepsis with need for intensive medical care; and severe kidney injury, often as the manifestation of a cardio-renal syndrome, with need for repeated hemodialysis. Clinical details of the nine cases which were cost outliers are described in Supplementary Table 1 . These cases were associated with an elaborate intensive medical therapy which accounted for considerably higher costs.

The higher total costs in frail patients were attributable to significant differences in costs incurred on IMC/ICU, on regular ward, for physiotherapy and laboratory services. The higher costs incurred on IMC/ICU and regular ward 


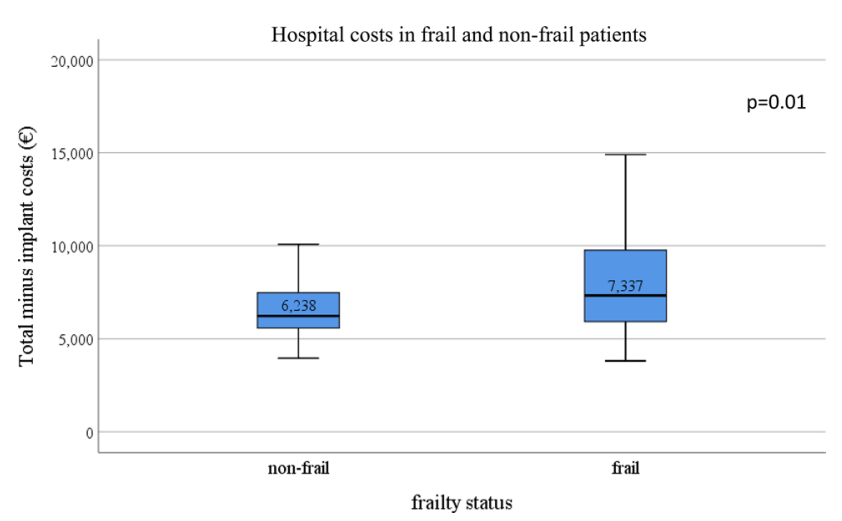

Fig. 2 Hospital costs in frail and non-frail patients

(personnel expenses for physician and nursing services, overhead costs for medication, other medical supply and medical and not-medical infrastructure) are time based allocated to a patient and therefore expected to increase with a prolonged stay.

Since costs and revenues might change over time, stratified analysis was performed by year of procedure performed. There was a trend for a decrease of total costs and total costs minus implant costs from the year 2014 to the year 2016 and no obvious temporal trend of revenues (Supplementary Table 2). The results of the total population with higher costs in frail patients and virtually no relevant difference of revenues between frail and non-frail patients was found in all 3 years of the study observation.

\section{Prolonged IMC/ICU stay}

The rate of patients with a prolonged IMC/ICU stay was significantly increased in frail $(n=38,36 \%)$ compared to non-frail patients $(n=23,19 \%, p=0.04)$. The causes of a prolonged IMC/ICU stay are listed in Table 3. All post-procedural complications associated with a prolonged stay were more frequent in frail patients.

\section{Discussion}

Frailty is a leading cause for high surgical risk and the decision for a TMVR approach in patients with mitral regurgitation. Although about half of patients undergoing TMVR are frail $[14,15,20]$, data on the impact of frailty on procedural health care utilization is lacking. Mean total costs without implant expenses were $32 \%$ higher in frail patients, and the association between frailty and costs persisted after excluding high cost outliers and was consistent across different definitions of frailty. Importantly, frailty was the only significant predictor of total costs when considering baseline patient characteristics including sex, age, comorbidities,
Table 3 Comparison of causes for prolonged stay. Data are presented as frequency and percentage

\begin{tabular}{|c|c|c|}
\hline & $\begin{array}{l}n=38 / 107 \\
\text { frail patients }\end{array}$ & $\begin{array}{l}n=23 / 122 \\
\text { non-frail } \\
\text { patients }\end{array}$ \\
\hline MVARC major or minor bleeding & $14(13.1 \%)$ & $7(5.7 \%)$ \\
\hline $\begin{array}{l}\text { Acute kidney injury requiring haemo- } \\
\text { dialysis }\end{array}$ & $3(2.8 \%)$ & $0(0 \%)$ \\
\hline Infection & $4(3.7 \%)$ & $2(1.6 \%)$ \\
\hline Haemodynamic instability/arrhythmias & $6(5.6 \%)$ & $5(4.1 \%)$ \\
\hline Respiratory failure & $4(3.7 \%)$ & $4(3.3 \%)$ \\
\hline Logistics/other & $7(6.5 \%)$ & $5(4.1 \%)$ \\
\hline
\end{tabular}

$B M I$ body-mass index, COPD chronic obstructive pulmonary disease, $E F$ ejection fraction, $G F R$ glomerular filtration rate, $I A D L$ instrumental activities of daily life, $M R$ mitral regurgitation, $M V A R C$ mitral valve academic research consortium, NYHA New York heart association, PAOD peripheral artery occlusive disease, TIA transient ischemic attack

NYHA functional class and history of previous cardiac surgery. The increase in hospital costs in frail patients was primarily the result of a prolonged stay on the IMC/ICU caused by minor medical complications.

Our data extend existing evidence on the role of frailty for adverse outcomes in various health care settings. A body of evidence exists on the effect of frailty on prolonged recovery time after surgical procedures; in particular, a higher rate of institutionalization, increased mortality [21,22] and the disproportionally high health care utilization associated with frailty in industrialized countries overall [23, 24]. Here, we show the necessity of prolonged postprocedural IMC/ICU and total hospital stay and associated increase in costs in the TMVR population. TMVR is a low stress intervention particularly developed for frail patients. In the setting of transcatheter aortic valve implantation [10], which is another minimal invasive procedure, frailty was a cost driver due to a prolonged length of stay, a high rate of complications and institutional discharge [25]. However, these results cannot be directly translated to the setting of TMVR. First, the burden of heart failure is higher in the TMVR population. Patients with severe aortic stenosis undergo a TAVI soon after symptoms arise, whereas mitral regurgitation (in particular secondary MR) is commonly associated with left ventricular failure and consequently these patients receive appropriate treatment (TMVR) after having already suffered from long-term symptomatic heart failure. Second, procedural complications are rare in the setting of TMVR and most often are not critical, whereas TAVI has the potential of early life-limiting complications, which occur more frequently in frail patients [26].

We have shown recently that MitraClip procedure shows similar technical and procedural efficacy in frail and nonfrail patients [15]. Major cardiac structural and vascular 
access site complications were also not different. So, what might be the reason for the increased length of stay on IMC/ ICU and regular wards? Frail patients were older, had a worse NYHA class and were generally sicker as reflected by the higher EuroScore II. However, frailty was the only predictor of hospital costs and comorbidities were not. A detailed analysis of underlying reasons for the prolonged hospital stay is beyond the scope of this study and partly impossible in a retrospective design since total hospital stay is the result of a complex interplay between medial, social, functional and logistic determinants. However, frail patients caused higher costs for laboratory services and physiotherapy, which are based on direct patient level data. Although these cost centre groups account for only a small absolute cost difference, these findings suggest that frail patients for example need more support to regain mobility/physical capabilities than non-frail patients. In support of the latter, frail patients have substantially worse disease independent measures of physical functioning both before and after TMVR than non-frail patients [15]. Furthermore, our analysis of medical causes of prolonged IMC/ICU stay demonstrated more minor complications or complications not directly associated with the TMVR procedure. Clinically severe complications such as haemodynamic compromise and dialysis might be generally more frequent in frail patients due to the higher baseline cardiac and extracardiac morbidity. For instance, baseline glomerular filtration rate was lower in frail patients which increases the risk of postprocedural renal failure. Prolonged respiratory failure and mechanical ventilation can be also explained by reduced cardiopulmonary reserve in frail patients but might also be attributable to muscle weakness and sarcopenia which are typical characteristics in frail patients [21]. We do not know whether the incidence of complications such as minor bleeding or infections overall are higher, or whether these complications are only more relevant for the clinical course of frail compared to non-frail patients. Such complications are usually only documented if clinically relevant or manifest and as such could not be systematically assessed in our retrospective analysis. However, considering the pathophysiological concept of frailty as increased vulnerability to stressors it seems plausible that mild bleeding anemia or inflammatory response might contribute to delayed recovery of frail patients and in consequence to longer hospital stay and higher costs [27].

Our findings have several important implications. First, from a methodological point of view cost analysis provides complementary data of patient outcomes to primary medical data. This is of major interest since frequency of complications might not differ in frail and non-frail patients but might have different impact on outcome and health care utilization. For instance, in patients undergoing TAVI there was a significant interaction between frailty status and access site on clinical outcome demonstrating that increased stress of transapical access was only of prognostic relevance in vulnerable, frail patients [28]. Second, frailty has a substantial impact on reimbursement of TMVR patients. Although on average the revenues exceeded the costs in frail and nonfrail patients, the reimbursement was not covering costs in only $7 \%$ of non-frail patients and in $22 \%$ of frail patients. This knowledge is valuable for a hospital's total cost calculation and resource allocation planning. Given the expected increase of frailty in the aging population, it should be considered to integrate frailty as a diagnosis determining case complexity and hence magnitude of revenue within the DRG based health care system. Our findings must not be interpreted as to deny TMVR in frail patients because of increased costs. In contrast, we observed a more pronounced symptomatic benefit of frail compared to non-frail patients after TMVR indicating a similar net cost-effectiveness. Third, physical frailty is regarded a potentially reversible health state. As such, the implementation of a frailty screening prior intervention and a tailored approach to disabilities of frail patients with early interventions during or even prior to the hospital stay may reduce length of stay and total costs in frail patients [29]. A positive impact of physical exercise, nutritional supplement and cognitive training on functional outcome has been reported, and geriatric-specific care protocols are discussed to shorten hospital length of stay in frail patients [30]. As TMVR compared to medical therapy alone has shown to result in a lower rate of hospitalization for heart failure and lower all-cause mortality within 24 months of follow-up in highly selected patients [31], further research should evaluate the cost-effectiveness or cost-utility of TMVR with regard to frailty.

\section{Study limitations}

When interpreting the data, it must be considered that prices, cost calculation and reimbursement systems differ worldwide, and thus absolute estimates may not be generalizable from the German DRG-based system to other health care systems. For example, the length of hospital stay after TMVR is longer in Germany [median 9 (6-15) days] than in the US [median 2 (1-5) days] [6, 7]. However, the underlying medical context of frailty with increased resource utilization after TMVR and associated costs as well as our findings on medical reasons for prolonged ICU/IMC stay will be generally applicable. Furthermore, due to the retrospective study design it was not possible to determine individual reasons for prolonged hospital stay and increased costs. With respect to the latter, is must be emphasized that costs associated with the centre groups of IMC/ICU and regular ward are not derived from patient level data but are estimations based on time spent. 
In order to estimate the resource use, data on costs was based on a case-based lump sum (i.e., G-DRG) which did not accurately reflect the real net effect of frailty on incurred costs. However, calculations based on individual patient data would have required a different study design applying a detailed process of cost calculation which was beyond the scope of this analysis.

\section{Conclusion}

Frailty is associated with a mean $32 \%$ increase of hospital costs in patients undergoing TMVR, which is primarily the result of a prolonged recovery and increased vulnerability to complications. These findings are valuable for a hospital's total cost calculation and resource allocation planning. Since frailty is regarded a potentially reversible health state, preventive interventions may help reduce costs in frail patients.

Funding Open Access funding enabled and organized by Projekt DEAL.

Open Access This article is licensed under a Creative Commons Attribution 4.0 International License, which permits use, sharing, adaptation, distribution and reproduction in any medium or format, as long as you give appropriate credit to the original author(s) and the source, provide a link to the Creative Commons licence, and indicate if changes were made. The images or other third party material in this article are included in the article's Creative Commons licence, unless indicated otherwise in a credit line to the material. If material is not included in the article's Creative Commons licence and your intended use is not permitted by statutory regulation or exceeds the permitted use, you will need to obtain permission directly from the copyright holder. To view a copy of this licence, visit http://creativecommons.org/licenses/by/4.0/.

\section{References}

1. Strandberg TE, Pitkala KH (2007) Frailty in elderly people. Lancet 369(9570):1328-1329. https://doi.org/10.1016/S0140 -6736(07)60613-8

2. Khan KT, Hemati K, Donovan AL (2019) Geriatric physiology and the frailty syndrome. Anesthesiol Clin 37(3):453-474. https ://doi.org/10.1016/j.anclin.2019.04.006

3. Chen X, Mao G, Leng SX (2014) Frailty syndrome: an overview. Clin Interv Aging 9:433-441. https://doi.org/10.2147/CIA.S4530 0

4. Back C, Hornum M, Olsen PS, Moller CH (2019) 30-day mortality in frail patients undergoing cardiac surgery: the results of the frailty in cardiac surgery (FICS) copenhagen study. Scand Cardiovasc J 53(6):348-354. https://doi.org/10.1080/14017 431.2019.1644366

5. Kwok CS, Lundberg G, Al-Faleh H, Sirker A, Van Spall HGC, Michos ED, Rashid M, Mohamed M, Bagur R, Mamas MA (2019) Relation of frailty to outcomes in patients with acute coronary syndromes. Am J Cardiol 124(7):1002-1011. https://doi. org/10.1016/j.amjcard.2019.07.003

6. Lee DH, Buth KJ, Martin BJ, Yip AM, Hirsch GM (2010) Frail patients are at increased risk for mortality and prolonged institutional care after cardiac surgery. Circulation 121(8):973978. https://doi.org/10.1161/CIRCULATIONAHA.108.841437

7. Tse G, Gong M, Nunez J, Sanchis J, Li G, Ali-Hasan-Al-Saegh $\mathrm{S}$, Wong WT, Wong SH, Wu WKK, Bazoukis G, Yan GX, Lampropoulos K, Baranchuk AM, Tse LA, Xia Y, Liu T, Woo J, International Health Informatics Study N (2017) Frailty and mortality outcomes after percutaneous coronary intervention: a systematic review and meta-analysis. J Am Med Dir Assoc 18(12):10971098. https://doi.org/10.1016/j.jamda.2017.09.002

8. Singh M, Rihal CS, Lennon RJ, Spertus JA, Nair KS, Roger VL (2011) Influence of frailty and health status on outcomes in patients with coronary disease undergoing percutaneous revascularization. Circ Cardiovasc Qual Outcomes 4(5):496-502. https:// doi.org/10.1161/CIRCOUTCOMES.111.961375

9. Goldfarb M, Bendayan M, Rudski LG, Morin JF, Langlois Y, Ma F, Lachapelle K, Cecere R, DeVarennes B, Tchervenkov CI, Brophy JM, Afilalo J (2017) Cost of cardiac surgery in frail compared with nonfrail older adults. Can Journal of Cardiol 33(8):10201026. https://doi.org/10.1016/j.cjca.2017.03.019

10. Joint Task Force on the Management of Valvular Heart Disease of the European Society of C, European Association for Cardio-Thoracic $\mathrm{S}$, Vahanian $\mathrm{A}$, Alfieri $\mathrm{O}$, Andreotti $\mathrm{F}$, Antunes MJ, BarónEsquivias G, Baumgartner H, Borger MA, Carrel TP, De Bonis M, Evangelista A, Falk V, Iung B, Lancellotti P, Pierard L, Price S, Schäfers H-J, Schuler G, Stepinska J, Swedberg K, Takkenberg J, Von Oppell UO, Windecker S, Zamorano JL, Zembala M (2012) Guidelines on the management of valvular heart disease (version 2012). Eur Heart J 33(19):2451-2496. https://doi.org/10.1093/ eurheartj/ehs 109

11. Feldman T, Foster E, Glower DD, Kar S, Rinaldi MJ, Fail PS, Smalling RW, Siegel R, Rose GA, Engeron E, Loghin C, Trento A, Skipper ER, Fudge T, Letsou GV, Massaro JM, Mauri L (2011) Percutaneous repair or surgery for mitral regurgitation. N Engl J Med 364(15):1395-1406. https://doi.org/10.1056/NEJMoa1009 355

12. Leon MB, Smith CR, Mack MJ, Makkar RR, Svensson LG, Kodali SK, Thourani VH, Tuzcu EM, Miller DC, Herrmann HC, Doshi D, Cohen DJ, Pichard AD, Kapadia S, Dewey T, Babaliaros V, Szeto WY, Williams MR, Kereiakes D, Zajarias A, Greason KL, Whisenant BK, Hodson RW, Moses JW, Trento A, Brown DL, Fearon WF, Pibarot P, Hahn RT, Jaber WA, Anderson WN, Alu MC, Webb JG, Investigators P (2016) Transcatheter or surgical aortic-valve replacement in intermediate-risk patients. $\mathrm{N}$ Engl J Med 374(17):1609-1620. https://doi.org/10.1056/NEJMoa1514 616

13. Afilalo J, Lauck S, Kim DH, Lefevre T, Piazza N, Lachapelle K, Martucci G, Lamy A, Labinaz M, Peterson MD, Arora RC, Noiseux N, Rassi A, Palacios IF, Genereux P, Lindman BR, Asgar AW, Kim CA, Trnkus A, Morais JA, Langlois Y, Rudski LG, Morin JF, Popma JJ, Webb JG, Perrault LP (2017) Frailty in older adults undergoing aortic valve replacement: the FRAILTY-AVR study. J Am Coll Cardiol 70(6):689-700. https://doi.org/10.1016/j. jacc.2017.06.024

14. Baldus S, Schillinger W, Franzen O, Bekeredjian R, Sievert H, Schofer J, Kuck KH, Konorza T, Mollmann H, Hehrlein C, Ouarrak T, Senges J, Meinertz T, German Transcatheter Mitral Valve Interventions I (2012) MitraClip therapy in daily clinical practice: initial results from the German transcatheter mitral valve interventions (TRAMI) registry. Eur J Heart Fail 14(9):1050-1055. https ://doi.org/10.1093/eurjhf/hfs079

15. Metze C, Matzik AS, Scherner M, Korber MI, Michels G, Baldus S, Rudolph V, Pfister R (2017) Impact of frailty on outcomes in patients undergoing percutaneous mitral valve repair. JACC Cardiovasc Interv 10(19):1920-1929. https://doi.org/10.1016/j. jcin.2017.07.042 
16. Baumgartner H, Falk V, Bax JJ, De Bonis M, Hamm C, Holm PJ, Iung B, Lancellotti P, Lansac E, Rodriguez Muñoz D, Rosenhek R, Sjögren J, Tornos Mas P, Vahanian A, Walther T, Wendler O, Windecker S, Zamorano JL, Group ESCSD (2017) 2017 ESC/ EACTS Guidelines for the management of valvular heart disease. Eur Heart J 38(36):2739-2791. https://doi.org/10.1093/eurheartj/ ehx391

17. Stone GW, Vahanian AS, Adams DH, Abraham WT, Borer JS, Bax JJ, Schofer J, Cutlip DE, Krucoff MW, Blackstone EH, Genereux P, Mack MJ, Siegel RJ, Grayburn PA, Enriquez-Sarano M, Lancellotti P, Filippatos G, Kappetein AP, Mitral Valve Academic Research C (2015) Clinical trial design principles and endpoint definitions for transcatheter mitral valve repair and replacement: part 1: clinical trial design principles: a consensus document from the mitral valve academic research consortium. J Am Coll Cardiol 66(3):278-307. https://doi.org/10.1016/j.jacc.2015.05.046

18. Judge JO, Schechtman K, Cress E (1996) The relationship between physical performance measures and independence in instrumental activities of daily living. The FICSIT group. Frailty and injury: cooperative studies of intervention trials. J Am Geriatr Soc 44(11):1332-1341. https://doi.org/10.1111/j.1532-5415.1996. tb01404.x

19. Nourhashemi F, Andrieu S, Gillette-Guyonnet S, Vellas B, Albarede JL, Grandjean H (2001) Instrumental activities of daily living as a potential marker of frailty: a study of 7364 communitydwelling elderly women (the EPIDOS study). J Gerontol Ser A Biol Sci Med Sci 56(7):M448-453. https://doi.org/10.1093/geron $\mathrm{a} / 56.7 . \mathrm{m} 448$

20. Sorajja P, Vemulapalli S, Feldman T, Mack M, Holmes DR Jr, Stebbins A, Kar S, Thourani V, Ailawadi G (2017) Outcomes with transcatheter mitral valve repair in the United States: an STS/ACC TVT registry report. J Am Coll Cardiol 70(19):2315-2327. https ://doi.org/10.1016/j.jacc.2017.09.015

21. Afilalo J, Alexander KP, Mack MJ, Maurer MS, Green P, Allen LA, Popma JJ, Ferrucci L, Forman DE (2014) Frailty assessment in the cardiovascular care of older adults. J Am Coll Cardiol 63(8):747-762. https://doi.org/10.1016/j.jacc.2013.09.070

22. Green P, Woglom AE, Genereux P, Daneault B, Paradis JM, Schnell S, Hawkey M, Maurer MS, Kirtane AJ, Kodali S, Moses JW, Leon MB, Smith CR, Williams M (2012) The impact of frailty status on survival after transcatheter aortic valve replacement in older adults with severe aortic stenosis: a single-center experience. JACC Cardiovasc Interv 5(9):974-981. https://doi.org/10.1016/j. jcin.2012.06.011

23. Hoeck S, Francois G, Geerts J, Van der Heyden J, Vandewoude M, Van Hal G (2012) Health-care and home-care utilization among frail elderly persons in Belgium. Eur J Public Health 22(5):671677. https://doi.org/10.1093/eurpub/ckr133

24. Simpson KN, Seamon BA, Hand BN, Roldan CO, Taber DJ, Moran WP, Simpson AN (2018) Effect of frailty on resource use and cost for Medicare patients. J Comp Eff Res 7(8):817-825. https://doi.org/10.2217/cer-2018-0029

25. Patel JN, Ahmad M, Kim M, Banga S, Asche C, Barzallo M, Mungee S (2020) Relation of frailty to cost for patients undergoing transcatheter aortic valve implantation. Am J Cardiol 125(3):469474. https://doi.org/10.1016/j.amjcard.2019.10.021

26. Anand A, Harley C, Visvanathan A, Shah ASV, Cowell J, MacLullich A, Shenkin S, Mills NL (2017) The relationship between preoperative frailty and outcomes following transcatheter aortic valve implantation: a systematic review and meta-analysis. Eur Heart J Qual Care Clin Outcomes 3(2):123-132. https://doi.org/10.1093/ ehjqcco/qcw030

27. Fried LP, Tangen CM, Walston J, Newman AB, Hirsch C, Gottdiener J, Seeman T, Tracy R, Kop WJ, Burke G, McBurnie MA (2001) Frailty in older adults: evidence for a phenotype. J Gerontol Ser A Biol Sci Med Sci 56(3):M146-156. https://doi. org/10.1093/gerona/56.3.m146

28. Drudi LM, Ades M, Asgar A, Perrault L, Lauck S, Webb JG, Rassi A, Lamy A, Noiseux N, Peterson MD, Labinaz M, Lefevre T, Popma JJ, Kim DH, Martucci G, Piazza N, Afilalo J (2018) Interaction between frailty and access site in older adults undergoing transcatheter aortic valve replacement. JACC Cardiovasc Interv 11(21):2185-2192. https://doi.org/10.1016/j.jcin.2018.06.037

29. Engelhardt KE, Reuter Q, Liu J, Bean JF, Barnum J, Shapiro MB, Ambre A, Dunbar A, Markzon M, Reddy TN, Schilling C, Posluszny JA Jr (2018) Frailty screening and a frailty pathway decrease length of stay, loss of independence, and 30-day readmission rates in frail geriatric trauma and emergency general surgery patients. J Trauma Acute Care Surg 85(1):167-173. https://doi. org/10.1097/TA.0000000000001931

30. Apostolo J, Cooke R, Bobrowicz-Campos E, Santana S, Marcucci M, Cano A, Vollenbroek-Hutten M, Germini F, D’Avanzo B, Gwyther H, Holland C (2018) Effectiveness of interventions to prevent pre-frailty and frailty progression in older adults: a systematic review. JBI Database Syst Rev Implement Rep 16(1):140 232. https://doi.org/10.11124/JBISRIR-2017-003382

31. Stone GW, Lindenfeld J, Abraham WT, Kar S, Lim DS, Mishell JM, Whisenant B, Grayburn PA, Rinaldi M, Kapadia SR, Rajagopal V, Sarembock IJ, Brieke A, Marx SO, Cohen DJ, Weissman NJ, Mack MJ, Investigators C (2018) Transcatheter mitral-valve repair in patients with heart failure. N Engl J Med 379(24):23072318. https://doi.org/10.1056/NEJMoa1806640 